\title{
Post-partum psychiatric disorders
}

\section{Tanvi Vijay Tuteja*, Geeta Madhav Niyogi}

Department of Obstetrics and Gynaecology, K. J. Somaiya Medical College and Research Centre, Mumbai, Maharashtra, India

Received: 05 June 2016

Accepted: 01 July 2016

\section{*Correspondence:}

Dr. Tanvi Vijay Tuteja,

E-mail: dr_tanvi@yahoo.com

Copyright: () the author(s), publisher and licensee Medip Academy. This is an open-access article distributed under the terms of the Creative Commons Attribution Non-Commercial License, which permits unrestricted non-commercial use, distribution, and reproduction in any medium, provided the original work is properly cited.

\begin{abstract}
Post-partum period is demanding period characterized by overwhelming biological, social and emotional changes. It requires significant personal and interpersonal adaptation, especially in case of primigravida. Childbearing from the standpoint of psychological medicine is the most complex event in human experience. Traditionally Inwood has classified post-partum psychiatric disorders (PPPD) as maternity blues, post-partum (postnatal) depression and puerperal psychosis (PP). However the spectrum of postpartum phenomenology is widely characterized by range of emotions from transient mood liability, irritability and weepiness to marked agitation, delusions, confusion and delirium. Untreated post-partum depression can have adverse long term effects. For the mother, the episode can be the precursor of chronic recurrent depression. For her children a mother's ongoing depression can contribute to emotional, cognitive and interpersonal problems in later life. And therefore a thorough knowledge of the same is important for all obstetrician and gynecologists.
\end{abstract}

Keywords: PPPD, Postpartum Blue, Depression, Psychosis

\section{INTRODUCTION}

Post-partum period is demanding period characterized by overwhelming biological, social and emotional changes. It requires significant personal and interpersonal adaptation, especially in case of primigravida. Childbearing from the standpoint of psychological medicine is the most complex event in human experience. Recently delivered mothers are vulnerable to the whole spectrum of general psychiatric disorders, as well as those resulting from the physical and psychological changes of childbirth. Traditionally Inwood has classified post-partum psychiatric disorders (PPPD) as maternity blues, post-partum (postnatal) depression and puerperal psychosis (PP). ${ }^{1}$

However the spectrum of postpartum phenomenology is widely characterized by range of emotions from transient mood liability, irritability and weepiness to marked agitation, delusions, confusion and delirium.
Perinatal mental illness is largely underdiagnosed and undertreated. $^{2}$ The post-partum non psychiatric depression is common complication of child bearing and occurs in $10-15 \%$ of all deliveries and as such represents a considerable public health problem affecting mother infant interaction and attachment. ${ }^{3}$ Hence early diagnosis and management of PPPD is extremely crucial.

Untreated post-partum depression can have adverse long term effects. For the mother, the episode can be the precursor of chronic recurrent depression. For her children a mother's on going depression can contribute to emotional, cognitive and interpersonal problems in later life.

Immediate psychosocial adjustments following delivery have been divided into 3 phases each lasting for a few days to a week. 


\section{Taking-in phase}

Patient is talkative, wishing to discuss the delivery experience in order to assimilate the birth and to resolve outstanding questions. Physically she is convalescing from the birth's experience and may be markedly fatigued. She is open and receptive welcoming assistance from care givers and family.

\section{Taking-hold phase}

Mother strives for independence and becomes an introvert. She becomes concerned about the resumption of her own bodily functions and about her infant. Infrequently she expresses anxiety over her abiity to care for her child. Since much of this phase occurs after discharge form hospital, caregivers must provide preparative training.

\section{Letting-go phase}

Mother establishes her maternal role patterns. Although still cantered on the infant her concerns also return to issues beyond the mother and infant world.

\section{Epidemiology}

Postpartum psychiatric disorder (PPD) is observed in 12/1000 childbearing women within 2-4 weeks following delivery. ${ }^{4,5}$ The onset of postpartum psychiatric disorder is sudden and acute in nature. ${ }^{6}$ It is seen as early as 2-3 days following delivery. The patient can have paranoid, grandiose or bizarre delusions, mood swings, confused thinking, and grossly disorganized behaviour and is usually characterized by a dramatic change from her previous functioning. Postpartum depression (PD) is observed in $10-13 \%$ of new mothers and maternal blues seen in $50-75 \%$ of postpartum women. ${ }^{8}$

A community based prospective study in India found out incidence of Postpartum psychiatric disorder in rural women to be around $11 \%$ which is comparable to incidence in western culture where $10-15 \%$ of all women are affected with PPD. ${ }^{7,9}$ In adolescent mothers it was around $26 \%$. $^{10}$

Postpartum psychiatric syndromes are seen more commonly $(81 \%)$ in patients below 25 years of age and majority of Indian women conceive during this part of childbearing age as the age of marriage is lower. Family history of mental illness was observed in $25 \%$ of patients. ${ }^{11}$

\section{Etiology}

The postpartum period is generally regarded as a period of maturation crisis similar to the adolescence and the menopause.

\section{The various stressors during the period include}

\section{Biological factors}

- Genetic factors: thuvel found that child red of women treated with postpartum psychosis has a significantly higher prevalence of psychiatric disorders; a similarity was seen in grandchildren of these women but difference was not statistically significant. $^{12}$

- Endocrinal factors: hypothalamic-pitutary gonadal axis: progesterone and estrogen levels drop suddenly during the first 7-10 days postpartum, while prolactin levels rise by $3^{\text {rd }}$ day and these changes are associated with affective disturbances. These relate only to postpartum blues. Bromocriptine, a drug which decreases prolactin levels and increases dopaminergic transmission is sometimes of benefit in treatment of bipolar depression.

- Cortisol: like gonadal hormones, cortisol levels increase during pregnancy, peak at birth and decline suddenly after childbirth. Abnormal cortisol levels are often associated with postpartum blues.

- Thyroid hormones: since the protein bound iodine levels during the first 9 months after childbirth are about $40 \%$ lower than those during the last trimester, a long lasting depression of thyroxine production has been postulated for psychiatric symptoms.

\section{Biochemical factors}

- Cyclic adenosine monophosphate: these levels decrease during postpartum period and are associated with postpartum depression.

- Amines: low levels of serotonin and tryptophan and high levels of norepinephrine metabolite have been found in postpartum blues. ${ }^{14,15}$

- Endorphins: the endorphin levels vary with esrogens and decreased levels associated with mood swings.

- Serum calcium: An association between elevated serum calcium and puerperal psychosis has been noted.

\section{Psychosocial factors}

Pregnancy and the transition to motherhood give birth to a variety of psychosocial stressors. A woman has to adjust to changes in her body image, her relationships with her husband and family members, her responsibilities and the manner in which she is perceived in society. ${ }^{16,17}$

\section{Risk factors associated with postpartum disorders}

Primigravida, unmarried mother, caesarean section or other perinatal complications, past history of psychotic illness, family history especially mother and sister having postpartum disorder, stressful life events during pregnancy and delivery, history of sexual abuse, 
vulnerable personality traits and social isolation or unsupportive spouse.

\section{Clinical features}

There has been long controversy as to whether puerperal illnesses are separate, distinct illnesses or episode of a known psychiatric disorder such as affective disorders or schizophrenic psychoses occur coincidently in puerperium or are precipitated by it. ${ }^{20}$

Postpartum disorders are classified as affective and others. Affective are typically divided into 3 categories.

- Postpartum blues

- Non psychotic postpartum depression

- Puerperal psychosis.

Table 1: Postpartum affective disorders: summary of onset, duration and treatment. ${ }^{20}$

\begin{tabular}{|c|c|c|c|c|}
\hline Disorder & Prevalence & Onset & Duration & Treatment \\
\hline $\begin{array}{l}\text { Postpartum } \\
\text { blues }\end{array}$ & $30-75 \%$ & $\begin{array}{l}\text { Day } 3 \\
\text { or } 4\end{array}$ & $\begin{array}{l}\text { Hours to } \\
\text { days }\end{array}$ & $\begin{array}{l}\text { No treatment } \\
\text { other than } \\
\text { reassurance }\end{array}$ \\
\hline $\begin{array}{l}\text { Postpartum } \\
\text { depression }\end{array}$ & $10-15 \%$ & $\begin{array}{l}12 \\
\text { months }\end{array}$ & $\begin{array}{l}\text { Week- } \\
\text { months }\end{array}$ & $\begin{array}{l}\text { Treatment } \\
\text { usually } \\
\text { required }\end{array}$ \\
\hline $\begin{array}{l}\text { Puerperal } \\
\text { psychosis }\end{array}$ & $0.1-0.2 \%$ & 2 weeks & $\begin{array}{l}\text { Week- } \\
\text { months }\end{array}$ & $\begin{array}{l}\text { Hospitalisati } \\
\text { on usually } \\
\text { required }\end{array}$ \\
\hline
\end{tabular}

\section{Postpartum blues}

Postpartum blues are known as "baby blues" or "maternity blues" is a phase of emotional liability following childbirth, characterized by frequent crying episodes, irritability, confusion and anxiety. However, elation might also be observed during the first few days following childbirth.

Postpartum blues is a very commonly observed puerperal mood disturbance, with estimates of prevalence ranging from $30-75 \%$. The symptoms arise within the first 10 days and peak around 3-5 days. ${ }^{22}$ Generally symptoms do not interfere with the social and occupational functioning of women, it is self-limiting with no requirement for active intervention except social support and reassurance from the family members. The symptoms include mood liability, irritability, tearfulness, and generalized anxiety and sleep and appetite disturbances. It can be attributed to changes in hormone levels compounded by stress following delivery. However if it persists for 2 weeks may make woman vulnerable to more severe form of mood disorders. ${ }^{23,24}$

It is the most common psychiatric disorder observed in the postpartum period occurring in $10-15 \%$ of women after delivery. It usually begins few days to weeks following delivery and most cases require treatment by a health professional. History of major depression increases risk by $25 \%$ and past history of postpartum depression increases recurrence rates by $25 \% .^{25}$ The signs and symptoms are generally the same as those associated with major depression occurring at other times, including depressed mood, anhedonia and low energy, anxiety and suicidal ideation.

\section{Postpartum psychosis}

It is the most severe and uncommon form of postnatal affective illness with rate of 1-2 episodes per 1000 deliveries. $^{26}$ It has an acute and abrut onset usually observed within the first 2 weeks following delivery or, at the most within 3 months postpartum and should be regarded as a psychiatric and obstetric emergency. ${ }^{27}$ Major risk factors are history of psychosis in previous pregnancies, history of bipolar disorder, family history of psychotic illnesss. ${ }^{28}$ Presenting symptoms are typically depressed or elated mood, disorganized behaviour, mood liability, delusions and hallucinations, infanticide (4\%) and suicidal $(5 \%)$ tendencies. ${ }^{29}$

\section{Others}

- Postpartum post-traumatic stress disorder: seen in around $5.6 \% .^{30}$ Generally characterized by tension, night mares, flashbacks and autonomic hyperarousal that can continue for some weeks or months and may reccur towards the end of next pregnancy ${ }^{31}$

- Anxiety disorders specific to puerperium Nocturnal vigilance characterized by the mother lying awake listening to infant's breathing, frequent checking ;resulting in sleep deprivation. Many mothers are exclusively warned and preoccupied about the health and safety of their children known as "maternal neurosis"

- Obsessions of child harm and other morbid preoccupations: can occur during gestation or within 6 weeks post-delivery. It is important to discourage avoidance of the child, and encourage cuddling and play, strengthening positive maternal feelings. A disorder akin to dysmorphophobia, based on the bodily changes resulting from pregnancy and childbirth, is common. These women complain of weight gain, stretch marks or scars. They are reluctant to undress in front of their husbands, avoid looking at themselves in bath or in the mirror, and sometimes avoid being seen in public. Conjugal jealousy is another disorder sometimes linked to pregnancy and childbirth, as an understandable reaction pregnancy's effect on sexual life and has been reported to reduce the woman's wish to breastfeed.

\section{Diagnosis}

Postpartum psychiatric disorders have largely been underdiagnosed, reiterating the fact that routine screening during postpartum visits must be done using "edinburgh 
postnatal depression scale" and "mood disorder questionairre". 32 Laboratory investigation and physical examination shoud be done to rule out organic causes like front temporal dementia/ frontal lobe tubercular and Sheehan's syndrome that mimic postpartum psychiatric disorders. $^{33-35}$

Tests include complete blood count, electrolytes, renal function test, glucose, vitamin B12, folate levels, Thyroid function tests, Serum calcium, urine examination, and urine drug screen, detailed neurological examination including CT/MRI to rule out ischemic or hemorrhagic changes.

\section{Treatment}

It is generally holistic includes reassurance, family and social support, psychoeducation, psychotherapy and/or pharmacotherapy in some cases. The essence of motherinfant services is the multi-disciplinary specialist team, including psychiatrists, psychologists, nurses and social workers.

\section{Non-pharmacological treatment}

Individual psychotherapy is an integral part of treatment, especially for females finding it difficult adjusting to motherhood and/or apprehensions about new responsibilities. Psychoeducation and emotional support for the partner and other family members are important. Patient and family members must be involved in the formulation of treatment plan. Respite care services should be recommended especially at night to minimize the patient's sleep disruption. .Interpersonal therapy may be helpful in some cases and is proven to reduce depressive symptoms and improve social adjustment. Postpartum psychosis demans separation from the infant, reassurance and emotional support. Peer support psycho education and psychotherapy are important interventions. ${ }^{36,37}$

\section{Pharmacotherapy}

In moderate to severe depression and postpartum psychosis medications are necessary. Safety and side effects of the medications during lactation must be addressed. The amount of medication to which an infant is exposed depends on several factors like maternal dosage of medication, timing and frequency of dosing, rate of maternal drug metabolism, and metabolism of the ingested drug in infant. ${ }^{38}$

Since most of the drugs are metabolized in the liver, premature infants and infants with compromised hepatic metabolism must be deferred from breastfeeding if mother is on psychotropic medications. Peak concentrations in breast milk are attained 6-8 hours after ingestion of medication. Therefore, breast feeding can be restricted to times when the breast milk drug concentration is lowest, that is, just before or after taking medication. $^{39}$

\section{Various medications used are}

\section{Anti-depressants}

$60 \%$ of mothers initiate nursing, and most of the antidepressants are excreted in breast milk. Sertraline, paroxetine, and nortriptyline may be preferred choices for nursing women. ${ }^{40}$

\section{Anti-psychotics}

Atypical anti psychotics are often the first line choice for psychotics and mania because of their tolerability. Olanzapine and quetiapine are considered most acceptable. $^{41}$ Chlorpromazine, haloperidol, and risepridone were classified as possible with breastfeeding, with medical supervision. Breastfed infants must be carefully observed for hydration status, excessive sedation, feeding difficulties, and failure to gain weight, which are possible signs of drug toxicity, and inform mothers to contact their physicians when they observe such symptoms.

\section{Lithium}

It is important for postpartum psychosis. Monitoring of lithium levels, thyroid and renal function, and adequate hydration is mandatory during the use of lithium. The use of lithium for breastfeeding mothers has generally been discouraged by American Academy of Pediatrics (AAP) because of concerns regarding secretion of the drug through breast milk. Lithium has been effective in decreasing relapse rates after subsequent pregnancies, although it is not clear if lithium should be restarted during pregnancy or immediately after parturition. ${ }^{42}$

\section{Anti-consultants}

Valproic acid or carbamazepine may be used to manage postpartum psychosis. The AAP reported that both these drugs were compatible with breastfeeding. Lomotrigine is Food and Drug Administration approved for bipolar depression, but no studies have examined its efficacy for postpartum psychosis and as it takes weeks for effects it has no role in acute phase and can be used for maintenance therapy. It is to be used with caution as high plasma levels seen in breastfeeding infants. ${ }^{43}$

\section{Benzodiazepines}

Have a role in acute psychosis. Intramuscular lorazepam and haloperidol can be used to achieve rapid tranquilization. Once patient is more stable oral agents can be used. However, they cannot be used as monotherapy for postpartum psychosis. 


\section{Electroconvulsive therapy}

It can rapidly yield symptomatic improvement in mothers with postpartum psychosis or severe postpartum depression, but it may be challenging for women who have not previously received any psychiatric treatment to accept this treatment option. The only risk of ECT to a breastfeeding infant are the medications given for anesthesia and muscle relaxation, but since these medications are short-acting, it is expected that there is minimal transfer to the infant. ${ }^{44}$

\section{Breastfeeding}

Women with postpartum psychosis should be advised against breastfeeding their infants. Both breastfeeding and nocturnal childcare are important causes of sleep loss, which in turn can lead to further mood instability particularly in women with bipolar disorder. Additionally, owing to psychotic state many women are incapable of breastfeeding. However for lactation suppression, dopamine agonists should be used cautiously as these drug cause psychosis in vulnerable women. ${ }^{45}$ Women who choose to breast feed must be informed about the fact that all psychotropic drugs are excreted in breast milk at varying concentrations. The decision of breastfeeding should be made after carefully weighing the risks and benefits to the mother as well as the infant.

\section{CONCLUSION}

Perinatal mental illness is under diagnosed and may have far reaching ramifications for the mother, her infant, her relationships with her partner and other family members. Prognosis of postpartum psychiatric disorders is generally good if diagnosed early and adequately treated, especially in cases of affective psychosis and brief psychotic disorders. Recurrence chances are high in postpartum psychosis and relapse in subsequent pregnancies can be as high as $25-40 \%$. Early identification of women at risk of developing postpartum psychiatric disorders and initiation of timely therapeutic approaches, consisting of combined pharmacological strategies and psychotherapeutic approaches as required; are the key factors for successful management of postpartum psychiatric disorders.

Funding: No funding sources Conflict of interest: None declared

Ethical approval: Not required

\section{REFERENCES}

1. Inwood DG. Recent advances in postpartum psychiatric disorders. Washington DC: American Psychiatric Press; 1985:31-56.

2. Marcus SM, Flynn HA, Blow FC, Burky KL. Depressive symptoms among pregnant women screened in obstetrics setting. J Womens Health. 2003; 12:373-80.

3. Geneva, Switzerland: WHO. WHO ICD-10. Classification of mental and behavioural disorders, 1992. Available at http://www.who.int/classifications/icd/en/bluebook.p df.

4. Kumar R. Postnatal mental illness. A transcultural perspective. Society Psychiatry Psychiatr Epidemiol. 1994;29:250-64.

5. Okano T, Numara J, Kumar R, Kaneko E, Tamaki R, Hanafusa I, et al. An epidemiological clinical investigation of postpartum psychiatric illness in Japanese mothers. J Affect Disorder. 1998;48:233.

6. Brockington IF, Cernik KF, Schofield EM, Downing AR, Francis AF, Keelan C. Puerperal psychosis: Phenomena and Diagnosis. Arch Gen Psychiatry. 1981;38:829-33.

7. O'Hara, Swain AM. Rates and risks of postpartum depression-A meta-analysis. Int Rev Psychiatry. 1996;8:37.

8. O'Hara MW, Schlechte JA, Lewis DA, Varner MW. Controlled prospective study of postpartum mood disorders: psychological, environmental and hormonal variables. J Abnorm Psychol. 1991;100:63-73.

9. Chandran M, Tharyan P, Muliyil J, Abraham S. Postpartum depression in a cohurt of women from rural area of Tamil Nadu, India. Incidence and risk factors. Br J Psychiatry. 2002;181:499-504.

10. Troutman BR, Cutrona CE. Non psychotic postpartum depression among adolescent mothers. J Abnorm Psychol. 1990;99:69-78.

11. Gautam S, Nijhawan M, Gehlot PS. Postpartum psychiatric syndromes- an analysis of 100 consecutive cases. Indian J Psychiatry. 1982;24:3836.

12. Thuwe I. Genetic factors in puerperal psychosis. Br J Psychaitry. 1974;125:378-85.

13. Hamilton JA. Postpartum Psychaitric Problems. St Louis: Mosby; 1962.

14. Stein G, Milton F, Bebbington P. Relationship between mood disturbances and free and total plasma tryptophan in postpartum women. $\mathrm{Br}$ Med $\mathrm{J}$. 1976;2:457-61.

15. Gard RPR, Handley SL, Parsons AD, Waldron G. A multivariate investigation of postpartum mood disturbances. Br J Psychiatry. 1986;148:576-5.

16. Shah LP, Parkar S, Pandit AS. Textbook of Postgraduate Psychiatry; 1999:369-375.

17. Paykel ES, Emms EM, Fietcher. Life events and social support in puerperal depression. $\mathrm{Br} \mathrm{J}$ Psychiatry. 1980;136:39-46.

18. Paykel ES, Emms EM, Fletcher J, Rassaby ES. Life events and social support in puerperal depression. $\mathrm{Br}$ J Psychiatry. 1980;136:339-46.

19. Sharma V, Mazmanian D. Sleep loss and postpartum psychosis. Bipolar Disord. 2003;5:98-105. 
20. Kendell RE, Chalmers JC, Platz C. Epidemiology of puerperal psychosis. Br J Psychiatry. 1987;150:66273.

21. Robling SA, Paykel ES, Dunn VJ. Psychological Medicine. 2000;30:1263-71.

22. Nonacs R, Cohen LS. Postpartum mood disorders. Diagnosis and treatment guidelines. J Clin Psychiatry. 1998;59:34-40.

23. O’Hara MW, Schelechte JA, Lewis DA, Wright EJ. Prospective study of postpartum blues. Biologic and psychosocial factors. Arch Gen Psychiatry. 1991;48:801-6.

24. Stein G. The maternity blues. In: Brockington IF, Kumar R, editors. Motherhood and mental illness London,UK: Academic Press; 1982:119-54.

25. Kendell RE, McGuire RJ, Connor Y, Cox JL. Mood changes in the first three weeks after child birth. J Affect Disord. 1981;3:317-26.

26. Henshaw C. Mood disturbance in the early puerperium: a review. Arch women's Ment health. 2003;6:33-42.

27. Kendell RE, Chalmers J Platz C. Epidemiology of Puerperal Psychoses. Br J Psychiatry. 1987;150:66273.

28. Altshuler LL, Cohen L, Szuba MP, Burt VT, Gitlin M, Mintz J. Pharmacologic management of psychiatric illness during pregnancy: dillemas and guidelines. Am J Psychiatry. 1996;253:592-606.

29. Nonacs R, Cohen LS. Postpartum mood disorders: diagnosis and treatment guidelines. J Clin Psychiatry. 1998;59:34-40.

30. Freidman SH, Cavney J, Resnick PJ. Child murder by parents and evolutionary psychology. Psychiatr Clin North Am. 2012;35:781-95.

31. Creedy DK, Shocket IM, Horsfall J. Childbirth and the development of acute trauma symptoms. Incidence and contributing factors. Birth. 2000;27:104-11.

32. Menage J. Post-traumatic stress disorder in women who have undergone obstetric and /or gynaecological procedures. A consecutive series of 30 cases of posttraumatic stress disorder. J Reprod Infant Psychol. 1993;11:221-8.
33. Moms-Rush JK, Freda MC, Bemstein PS. Screening for postpartum disorder in an inner-city population. Am J Obstet Gynecol. 2003;188:1217-9.

34. Dell DL, Halford JJ. Dementia presenting as postpartum depression. Obstet Gynecol. 2002;99:925-8.

35. Stavrou P, Sgouros S. Frontal lobe tuberculoma masquerading as postnatal depression. $\mathrm{Br} \quad \mathrm{J}$ Neurosurg. 2002;16:74.

36. Gautam P, Bhatia MS, Rathi A, Kaur J. Sheehan's syndrome with psychosis: a rare case presentation. Delhi J Psychiatry. 2014;17:211-3.

37. Frank E, Kupfer DJ, Thase ME, Mallinger AG, Swartz HA. Two year outcomes for interpersonal and social rhythm therapy in individuals with bipolar disorder. Arch Gen Psychiatry. 2005;62:996-1004.

38. Turner KM, Sharp D, Folkes L, Chew Graham C. Women's views and experiences of antidepressants, metabolism and dosing across pregnancy and early postpartum depression: a qualitative study. Fam Pract. 2008;25:450-5.

39. Bledsoe SE, Grote NK. Treating depression during pregnancy and in the postpartum: a preliminary meta-analysis. Res Soc Work Pract. 2006;16:109-20.

40. Weissman AM, Levy BT, Hartz AJ, Bentler S. Polled analysis of antidepressant levels in lactating mothers, breast milk and nursing infants. Am J Psychiatry. 2004;161:1066-78.

41. Klinger G, Stahl B, Fusar-Poli P, Merlob P. Antipsychotic drugs and breastfeeding. Pediatr Endocrinol rev. 2013;10:308-17.

42. Sachs HC. Committee on drugs. The transfer of drugs and therapeutics into human breast milk: An update on selected topics. Pediatrics. 2013;132:796809.

43. Bergink V, Bouvy PF, Vervoort JS, Kushner SA. Prevention of postpartum psychosis and mania in women at high risk. Am J Psychiatry. 2012;169:60915.

44. Focht A, Kellner CH. Electroconvulsive therapy (ECT) in the treatment of postpartum psychosis. J ECT. 2012;28:31-3.

45. Brockington IF. New York,USA: Oxford University Press. Puerperal psychosis. In: Motherhood and mental illness; 1996:200-284.

Cite this article as: Tuteja TV, Niyogi GM. Postpartum psychiatric disorders. Int J Reprod Contracept Obstet Gynecol 2016;5:2497-2502. 